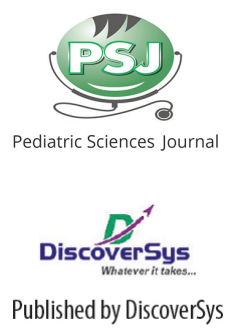

${ }^{1}$ Department of Child Health, Faculty of Medicine, Universitas Brawijaya, Saiful Anwar General Hospital, Malang, Indonesia

*Corresponding to:

Hajeng Wulandari; Department of Child Health, Faculty of Medicine, Universitas Brawijaya, Saiful Anwar General Hospital, Malang, Indonesia;

hajeng.wulandari@gmail.com

Received: 2020-09-28 Accepted: $2020-12-02$ Published: 2020-12-24

\title{
Post-Traumatic Stress Disorder Following Surgery: A Case Report of A Three-Year-Old Child with Deep Dermal Burn Injury
}

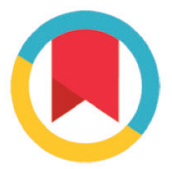

CrossMark

\author{
Hajeng Wulandari, ${ }^{1 *}$ Ariani $^{1}$
}

\section{ABSTRACT}

Introduction: In the past few years, there has been increased recognition that children, who have a history of traumatic incidences, can develop post-traumatic stress disorder (PTSD), just like in adults.

Case: We presented a case of PTSD in a 3-year-old child hospitalized in the hospital for two days due to combustion (deep dermal burn injury) in his left hand, stomach, and both of his legs. The patient started to experience parasomnia such as nightmares, raves, difficulty to sleep and awakened from sleep (for one month from the beginning of wound treatment and debridement). The patient also had two re-experiencing symptoms: nightmare and emotional distress (anxiety, anger) after a traumatic stimulus. From his temperament scale and character assessment, there was dysregulation disorder. From the PEDSQL parent's reports, there was also decreased quality of life.

Conclusion: First-line therapy of PTSD for the pediatric population is supportive psychotherapy with trauma-focused cognitive behavioral therapy (TF-CBT) that results in a remarkable improvement in child's psychiatric outcome.

Keywords: post-traumatic stress disorder (PTSD), parasomnia, pediatric, psychiatric

Cite this Article: Wulandari, H., Ariani. 2020. Post-Traumatic Stress Disorder Following Surgery: A Case Report of A Three-Year-Old Child with Deep Dermal Burn Injury. Pediatrics Sciences Journal 1(2) : 54-56.

\section{INTRODUCTION}

\section{Post-Traumatic Stress Disorder}

Post-Traumatic Stress Disorder (PTSD) is a group of symptoms after experiencing an occasion that causes trauma such as death, life-threatening injury or sexual abuse. These traumatic occasions may happen directly (suffered by themselves) or indirectly (by seeing others suffering). ${ }^{1}$

This group of symptoms happens at least for one month, causing distress or functional disorder (social or occupational), and medicine did not cause the symptoms. Based on DSM-V criteria, there are four categories of symptoms: re-experiencing the event, avoidance, negative feeling/ thinking after a traumatic occasion, and hyper-arousal (Table 1$).{ }^{1}$

Effective treatment for PTSD children is trauma-focused cognitive behavioral therapy (TFCBT) and play therapy. TF-CBT is a cognitive behavior treatment in which children will be given psychotherapy about the natural process of their traumatic occasion, then gradually will be faced to their fear stimulus, and the last process is restructuring cognitive/ mind to change the negative thinking about traumatic incident. TFCBT maybe given to PTSD patients 3 to 18 years old. TF-CBT consists of some sessions, those are children with parents session and separated parents session (Figure 1). ${ }^{2}$
Play therapy is an effective therapy to overcome PTSD in children by playing. The doctor/counselor will use toys to communicate traumatic incidents without words. The doctor/counselor will use a toy and showing the traumatic incident slowly by roleplay.

In this patient, the counselor plays the role of a doctor or nurse who operates or treats a wound at a sick doll. By playing, the counselor will instill that events the patient deemed painful is a good purpose. $^{3}$

\section{Medication for Paediatric Patients with PTSD}

Medication therapy is only given to pediatric patients who do not improve with supportive psychotherapy. Some literature does not suggest the usage of antidepressants, mainly Selective Serotonin Re-uptake Inhibitors/ SSRI. This is different in adults' PTSD, where the studies show SSRI usage effective in overcoming the PTSD symptoms. ${ }^{4}$

The case series shows prazosin usage; agonist a-1 adrenergic is useful for treating sleep disorder and nightmares in children with PTSD. A study by Keeshin BR et al. shows prazosin (dosage 0,02- 0,3 $\mathrm{mg} / \mathrm{kg}$ of BW) in 34 pediatric patients with PTSD may improve nightmare and sleep quality (pre versus post-therapy $\mathrm{p}=<0,001)$. Besides prazosin, guanfacine and clonidine are also useful for pediatric patients with PTSD. ${ }^{4}$ 
Table 1. Symptoms Category of PTSD

\begin{tabular}{ccl}
\hline No. & Category of Symptoms & \multicolumn{1}{c}{ Symptoms } \\
\hline 1. & Re-experiencing the event & $\begin{array}{l}\text { Disappointing/ sad memories Nightmares } \\
\text { Flashbacks Emotional distress due to } \\
\text { traumatic occasion } \\
\text { Physical disorder after traumatic occasion }\end{array}$ \\
& Avoidance & $\begin{array}{l}\text { Avoidance of traumatic occasion } \\
\text { Effort to avoid traumatic thinking/ feeling }\end{array}$ \\
2. $\quad \begin{array}{l}\text { Negative feeling/ } \\
\text { thinking after traumatic } \\
\text { occasion }\end{array}$ & $\begin{array}{l}\text { Negative affect Excessive negative } \\
\text { assumption about someone/ something } \\
\text { Blaming themselves as the cause of } \\
\text { traumatic occasion Decreased of interest } \\
\text { in doing preferred activity Feeling lonely } \\
\text { Difficult in thinking and feeling positively }\end{array}$ \\
& & $\begin{array}{l}\text { Irritable Doing risky action Excessive } \\
\text { reaction of something Difficult to focus } \\
\text { Sleep disorder }\end{array}$ \\
& &
\end{tabular}

Connor DF et al. show that guanfacine extendedrelease with a mean dosage of $1.19 \mathrm{mg} \pm 0.35 \mathrm{mg}$ $(0.03 \mathrm{mg} / \mathrm{kg} \pm 0.01 \mathrm{mg} / \mathrm{kg})$ significantly affects the severity of PTSD symptoms in pediatric which scored by UCLA reaction index. This patient's parents report that cluster B (re-experiencing), cluster C (avoidance), and cluster D (hyper-arousal) have significant improvement. ${ }^{4,6}$

Clonidine as agonist receptor $\alpha-2$ is sufficient to improve nightmares and sleep disorders inpatient with PTSD. A report by Porter and Bell shows that usage of $0.05 \mathrm{mg}$ clonidine in pediatric patients (11 years old) with PTSD improves aggression symptoms and nightmares inpatients. The symptoms improved after the dosage is increased to $0.1 \mathrm{mg}$, three times per day. Two other cases by Alao et al. also show depression, nightmares, and flashbacks in PTSD patients were improved after two weeks with clonidine (dosage $0.1 \mathrm{mg}, 3 \mathrm{x} /$ day).

PTSD symptoms, which were not improved after prazosin usage, resulted in improvement after regiment change to clonidine (dosage $0,1 \mathrm{mg}$ ), titrated to $0,3 \mathrm{mg}, 3 \mathrm{x} / \mathrm{day}$ for two weeks. Other psychiatric medicine such as second-generation antipsychotic and anticonvulsant have inadequate clinical impact compared to their adverse events. ${ }^{7-9}$

\section{PTSD as risk factor of Dementia}

Treatment of PTSD is essential because PTSD is reducing the patient's life quality and causing another cognitive impairment, such as dementia. A study by Bonanni L et al., 2018 shows PTSD is related to semantic frontotemporal dementia. In this study, from 46 PTSD patients who were monitored prospectively for 6-10 years, there were
8 patients (13\%) acquire dementia, the details are as follows 1 patient acquires Alzheimer's disease, 1 patient acquires dementia with Lewy's body, dan 6 patients acquire frontotemporal dementia. ${ }^{10}$

Moreover, from a retrospective analysis of 849 patients with dementia, 38 patients $(4.5 \%)$ have PTSD history. Of those 38 patients, the most common is frontotemporal dementia. Frontotemporal dementia among dementia patients with PTSD history (38 patients) is higher than frontotemporal dementia in overall dementia patients. $(16 \%$ compared to $5 \%, \mathrm{p}=0,005) .{ }^{10}$

\section{CASE PRESENTATION}

A-3-year-old boy had recurrent nightmares and raves (talking wildly) experiences in the night accompanied with body stiffness for 29 days during treatment in Saiful Anwar general hospital. According to his parents, he dreamt that he was hospitalized and raved that he did not want to because he was afraid of a doctor and nurse. He was hospitalized in another hospital for two days due to combustion (burn injury) in his left hand, stomach, and both of his legs. He got combustion because of jumping into hot water when playing with his friends.

There was no past illness and family disease history linked to a psychiatric disorder. His birth and nutrition history was regular. His immunization history was appropriate to his age. The developmental history was regular. He was the first of two children. There was a deep dermal burn injury in his left hand, stomach, and lower extremities from the first physical examination. His anthropometric status was expected, but there was a dysregulation disorder from the temperament scale and character assessment. From the PEDSQL parent's reports, there was also decreased quality of life.

\section{DISCUSSION}

Patients with PTSD must experience at least one symptom of re-experiencing the event, one symptom of avoidance from a traumatic stimulus, two symptoms of negative feeling/ thinking after a traumatic occasion, and two hyperarousal symptoms. This patient was diagnosed with PTSD because from the beginning of wound treatment and debridement, the patient started to experience nightmares, raves, difficulty to sleep and awakened from sleep for one month. The patient had two symptoms of re-experiencing the event such as nightmare and emotional distress (anxiety, anger) after traumatic stimulus; one symptom of avoidance, such as avoiding the traumatic occasion; 

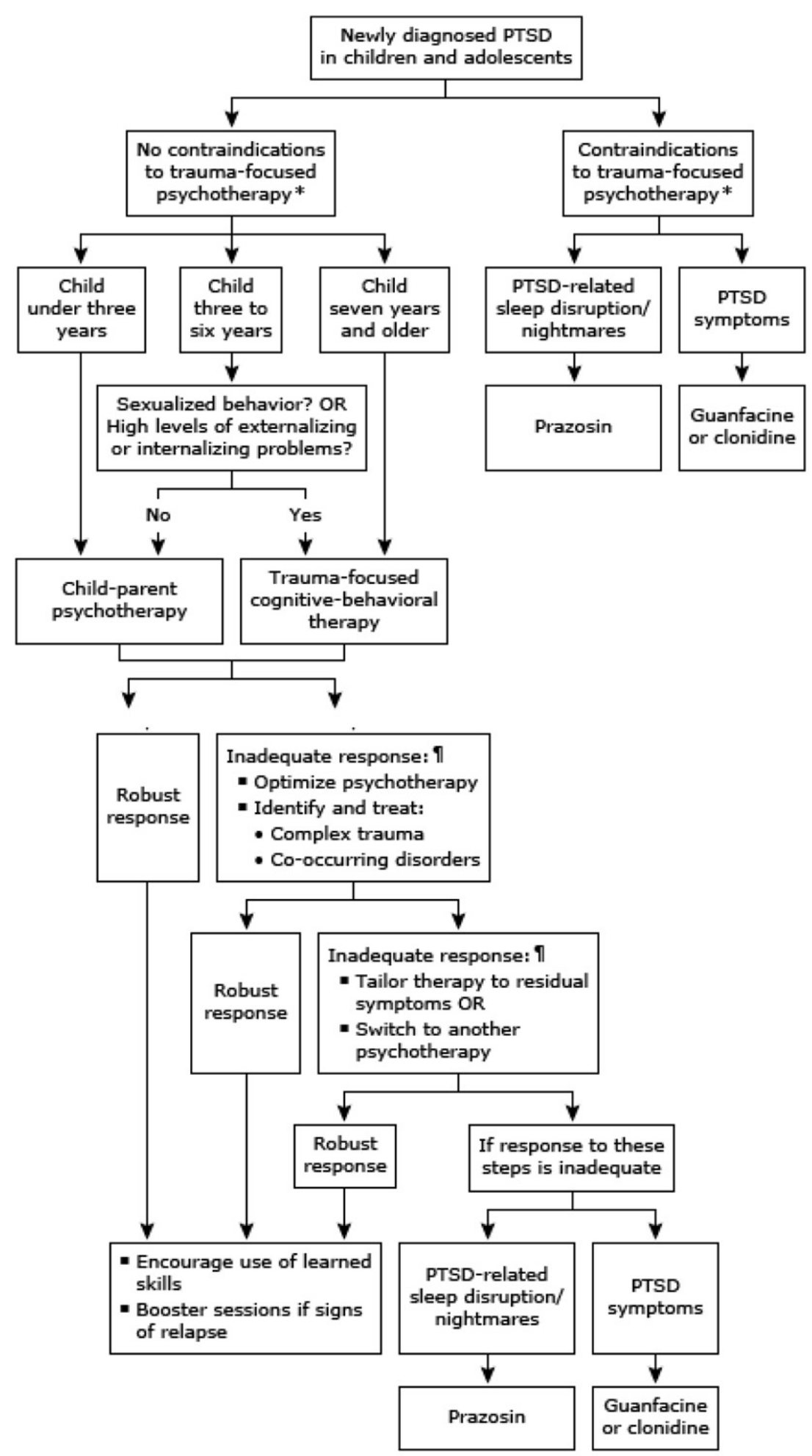

Figure 1. Algorithm of PTSD Treatment in Paediatric First line therapy of PTSD is trauma focused cognitive behavioural therapy (TF-CBT). After this therapy is completed (12-25 sessions), the patient is re-assessed. If there is no significant improvement from PTSD symptoms, the patient will receive medicamentosa therapy, such as prazosin, guanfacine, or clonidine. Medication therapy may be received from the beginning if there is contraindication of psychotherapy (CBT/ play therapy), for instance the patient suffers acute psychotic, attempted suicide, or severe cognitive impairment. $^{5}$ two symptoms of negative thinking/ feeling as a dangerous assumption to someone/ something (in this case is health workers), and negative affect; and three symptoms of hyperarousal, such as irritable, insomnia, and easy to be startled by mild stimulus reminding of a traumatic incident. The patient was treated with supportive psychotherapy by roleplaying therapy as first line therapy of PTSD for the pediatric population.

\section{FUNDING}

None

\section{CONFLICT OF INTEREST}

None

\section{REFERENCES}

1. US Department of Veteran Affairs, "PTSD and DSM-5 PTSD: National Center for PTSD,” 2018. https://www. ptsd.va.gov/professional/treat/essentials/dsm5_ptsd.asp (accessed Oct. 31, 2020).

2. N. Copeland-Linder, "Posttraumatic stress disorder.," Pediatr. Rev., vol. 29, no. 3, pp. 103-104; discussion 104, 2008, doi: 10.1542/pir.29-3-103.

3. B. Shrinivasa, M. Bukhari, G. Ragesh, and A. Hamza, "Therapeutic intervention for children through play: An overview," Arch. Ment. Heal., vol. 19, no. 2, p. 82, 2018, doi: 10.4103/amh.amh_34_18.

4. B. R. Keeshin, Q. Ding, A. P. Presson, S. J. Berkowitz, and J. R. Strawn, "Use of Prazosin for Pediatric PTSD-Associated Nightmares and Sleep Disturbances: A Retrospective Chart Review," Neurol. Ther., vol. 6, no. 2, pp. 247-257, Dec. 2017, doi: 10.1007/s40120-017-0078-4.

5. Wolters Kluwer, "Approach to treating posttraumatic stress disorder in children andadolescents - UpToDate," 2020. https://www.uptodate.com/contents/approach-totreating-posttraumatic- stress-disorder-in-children-andadolescents (accessed Oct. 31, 2020).

6. D. F. Connor, D. J. Grasso, M. D. Slivinsky, G. S. Pearson, and A. Banga, "An open-label study of guanfacine extended release for traumatic stress related symptoms in children and adolescents," J. Child Adolesc. Psychopharmacol., vol. 23, no. 4, pp. 244-251, May 2013, doi: 10.1089/cap.2012.0119.

7. A. Alao, J. Selvarajah, and S. Razi, "The use of clonidine in the treatment of nightmares among patients with comorbid PTSD and traumatic brain injury," Int. J. Psychiatry Med., vol. 44, no. 2, pp. 165-169, Jan. 2012, doi: 10.2190/ PM.44.2.g.

8. M. R. Belkin and T. L. Schwartz, "Alpha-2 receptor agonists for the treatment of posttraumatic stress disorder," Drugs Context, vol. 4, Aug. 2015, doi: 10.7573/dic.212286.

9. D. M. Porter and C. C. Bell, "The use of clonidine in post-traumatic stress disorder," J. Natl. Med. Assoc., vol. 91, no. 8, pp. 475-477, Aug. 1999, Accessed: Oct.31, 2020. [Online]. Available: /pmc/articles/ PMC2608446/?report=abstract.

10. L. Bonanni et al., "Post traumatic stress disorder heralding the onset of semantic frontotemporal dementia," $J$. Alzheimer's Dis., vol. 63, no. 1, pp. 203-215, 2018, doi: 10.3233/JAD-171134.

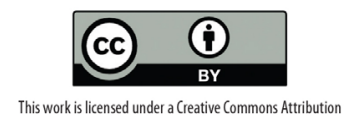

